\title{
Sensitivity of Wheat Genotypes to a Toxic Fraction Produced by Cephalosporium gramineum and Correlation with Disease Susceptibility
}

\author{
M. Rahman, C. C. Mundt, T. J. Wolpert, and O. Riera-Lizarazu
}

First, second, and third authors: Department of Botany and Plant Pathology, 2082 Cordley, Hall, Oregon State University, Corvallis 97331; and fourth author: Department of Crop and Soil Science, 117 Crop Science Building, Oregon State University, Corvallis 97331. Accepted for publication 1 April 2001.

\begin{abstract}
Rahman, M., Mundt, C. C., Wolpert, T. J., and Riera-Lizarazu, O. 2001. Sensitivity of wheat genotypes to a toxic fraction produced by Cephalosporium gramineum and correlation with disease susceptibility. Phytopathology 91:702-707.

Cephalosporium stripe is an important disease of winter wheat (Triticum aestivum) in several areas of the world, especially where stubble mulch and early seeding are practiced to maintain soil moisture and prevent erosion. We developed a procedure to mass-produce a toxic fraction produced by Cephalosporium gramineum through a modification of the method of Kobayashi and Ui. Exposure of excised wheat leaves to a concentration of $60 \mu \mathrm{l} / \mathrm{ml}$ of the toxic fraction for $72 \mathrm{~h}$ produced distinct wilting symptoms that allowed us to distinguish toxin-sensitive wheat genotypes in a repeatable manner. Twenty wheat genotypes belonging to four distinct germ plasm groups (common, club, durum, and synthetic) were evaluated. Variation in toxin sensitivity of wheat geno-

types was mostly at the level of the germ plasm group, and all differences among the four germ plasm groups were highly significant $(P<$ $0.001)$ based on linear contrasts. Seventeen winter wheat genotypes representing the common, club, and durum germ plasm groups were planted in C. gramineum-infested fields at two locations. The logarithm of the percentage of tillers showing whitehead symptoms at each of the two locations was significantly $(P<0.0001)$ correlated with wilting symptoms measured by the toxin assay $(r=0.80$ and 0.84$)$. The common wheat genotypes were all sensitive to the toxic fraction, but showed a substantial range of disease reactions in the field. However, we found no case of a toxin-insensitive genotype being susceptible in the field. These results suggest that toxin insensitivity may be an important mechanism of resistance to Cephalosporium stripe, but that other mechanisms are operative as well. The toxin assay may be useful as an initial screening procedure to reduce the number of genotypes to be tested in the field.
\end{abstract}

Cephalosporium stripe of wheat, caused by Cephalosporium gramineum Nisikado \& Ikata (Hymenula cerealis Ell. \& Ev.), is an important monocyclic vascular disease of winter wheat in many parts of the world, including Europe, eastern Africa, Japan, several of the northern U.S. states, and adjoining Canadian provinces $(4,8,12,26)$. The causal agent is a facultative fungal parasite that enters wheat roots in the fall and winter and colonizes the vascular system. Symptoms can include general chlorosis and diagnostic chlorotic leaf striping. Severe infections can cause wilting, leaf necrosis, stunting, and prematurely ripening heads (whiteheads) in the spring and summer (31). Under favorable conditions, the disease can cause as much as $80 \%$ yield loss (13). Colonized residue is returned to the soil after grain harvest and serves as the source of primary inoculum. Conidia produced on the residue infect the next crop to complete the disease cycle. In the absence of hosts, the fungus oversummers as a saprophyte in wheat debris and can remain viable in superficial wheat straw for at least 3 years $(6,17)$.

Cultural controls for Cephalosporium stripe (delayed planting, burning of crop residue, and deep plowing) are either economically infeasible or increase soil erosion $(2,18,29)$, and no chemicals are registered for control of the disease. The development of host resistance currently offers the best hope for control of Cephalosporium stripe. Although no wheat cultivars show complete resistance to Cephalosporium stripe, there is considerable variation in the degree of resistance among cultivars (7,21-23), and repeated planting of moderately resistant cultivars may reduce

Corresponding author: C. C. Mundt; E-mail address: mundtc@bcc.orst.edu

Publication no. P-2001-0507-01R

(C) 2001 The American Phytopathological Society both the incidence and severity of Cephalosporium stripe (30). However, current methods available to identify resistance in breeding programs are variable and prohibitively time-consuming $(7,9,24,35)$.

The symptoms of Cephalosporium stripe suggest the involvement of pathogen-produced toxins or xylem-plugging compounds, which have led to investigations of the production of antibiotics, toxins, and extracellular polysaccharides by the pathogen (28). Spalding et al. (32) found that extracellular polysaccharides produced by the fungus resulted in xylary plugging; however, Wiese (36) reported that occlusions were due to fungal proliferation that developed only after lateral extension of leaf striping. Kobayashi and Ui $(15,16)$ isolated and characterized Graminin A from culture filtrates of $C$. gramineum. This toxic compound causes yellowing of excised leaves at concentrations of $25 \mu \mathrm{g} / \mathrm{ml}$ (16). The toxin was structurally similar to Gregatin A, a compound isolated from culture filtrates of $C$. gregatum, which mimicked the symptoms of brown stem rot of soybeans; however, Graminin A was more selective for wheat. Graminin A possesses antimicrobial activity and affects stomate function in the same manner as infection by $C$. gramineum (11). The goals of our study were to determine if sensitivity of wheat genotypes to toxin is associated with susceptibility to Cephalosporium stripe and to evaluate the utility of an in vitro produced toxic activity as a tool to screen wheat genotypes for resistance.

\section{MATERIALS AND METHODS}

Laboratory assays and biological materials. Twenty wheat genotypes were evaluated, representing four taxonomic groups: common, club, durum, and synthetic. Common wheats, Triticum aestivum L. (AABBDD), included nine soft white winter wheat cultivars and one soft white winter wheat breeding line that are 
adapted to the Pacific Northwest (PNW) region of the United States, and one hard red cultivar, Opata 85 . Opata 85 is a spring wheat cultivar developed at the International Maize and Wheat Improvement Center (CIMMYT) and is a parent of the International Triticeae Mapping Initiative (ITMI) mapping population (34). Club wheats are hexaploid (AABBDD) T. aestivum types with compact heads, and originate from a different and substantially smaller gene pool than the common wheats. We examined five winter club wheat cultivars adapted to the PNW. Durum wheat genotypes, T. turgidum (AABB), included two advanced winter durum lines from the Oregon State University wheat-breeding program and one CIMMYT spring durum wheat cultivar (Altar 84) that is a "grandparent" of the ITMI mapping population. The synthetic hexaploid wheat was M6 (W-7984), the other parent of the ITMI population. M6 was produced by crossing cv. Altar 84 with an accession of Aegilops tauschii (TA 2465, DD), followed by doubling chromosome number with colchicine to obtain a synthetic hexaploid.

We evaluated 112 recombinant inbred lines from the cross between M6 and cv. Opata 85. Seed for the recombinant inbred line population, M6, and cv. Opata 85 were obtained from C. O. Qualset (Genetic Resources Conservation Program, University of California, Davis). Seed for the three durum genotypes were obtained from K. Ammar (Dept. of Crop and Soil Science, Oregon State University, Corvallis).

Ten seeds of each genotype were planted in $10-\mathrm{cm}$ plastic pots containing an organic soil mix and fertilized with the recommended rate of Miracle Gro (Stern's Miracle-Gro Products Inc., Port Washington, NY) at 7 days after planting. Pots were placed in a growth chamber in a completely randomized design at $21^{\circ} \mathrm{C}$ with a $16-\mathrm{h}$ photoperiod.

C. gramineum-infected wheat stems were collected from a naturally infested wheat field near Dufur, OR. An isolate was obtained by placing a surface-sterilized stem piece on potato dextrose agar (PDA). The culture was maintained on PDA at 5 to $7^{\circ} \mathrm{C}$ for use in subsequent laboratory assays.

Extraction of toxic fraction. Culture conditions and ethyl acetate extraction of the toxic fraction were first done according to the methods of Kobayashi and Ui (16). The ethyl acetate extract produced yellowing of excised wheat leaves at low concentrations and wilting at higher concentrations. Thin layer chromatography (Silica gel 60; EM Science, Hawthorne, NY) of the extract developed in chloroform/methanol (98:2, vol/vol) (16) and produced dark blue spots under UV radiation, consistent with the presence of Graminin A (15). Extraction methodology was subsequently modified to further refine the toxic substance and increase its yield.

Nine liters of broth were prepared by mixing $50 \mathrm{~g}$ of sucrose, $1.3 \mathrm{~g}$ of $\mathrm{K}_{2} \mathrm{HPO}_{4}, 1 \mathrm{~g}$ of $\mathrm{KH}_{2} \mathrm{PO}_{4}, 0.5 \mathrm{~g}$ of $\left(\mathrm{NH}_{4}\right)_{2} \mathrm{SO}_{4}$, and $0.5 \mathrm{~g}$ of $\mathrm{MgSO}_{4} \cdot 7 \mathrm{H}_{2} \mathrm{O}$ in each liter of distilled water. The medium was dispensed in 500-ml flasks ( $200 \mathrm{ml}$ per flask) and autoclaved at $121^{\circ} \mathrm{C}$ and $15 \mathrm{lbs} / \mathrm{in}^{2}$ for $15 \mathrm{~min}$. A total of $50 \mathrm{ml}$ of sterile water was used to scrape each PDA plate of $C$. gramineum with a sterile glass slide, and two subsequent washings. The spore suspension from the plate was added to a 500-ml flask containing $100 \mathrm{ml}$ of potato dextrose broth that was used as a seed flask. This flask was shaken on a Burrell Wrist-Action Shaker (Burrell Corp., Pittsburgh) for $72 \mathrm{~h}$ to raise the spore concentration to approximately 1.3 to $1.5 \times 10^{8} / \mathrm{ml}$. The spore suspension was added to each flask to attain $2 \times 10^{5}$ spores per $\mathrm{ml}$. At $24 \mathrm{~h}$ after inoculation, flasks were shaken well and incubated in standing culture for 35 days at $25^{\circ} \mathrm{C}$.

After 35 days of incubation, broth was passed through a kitchen sieve and filtered through $18.5-\mathrm{cm}$ Whatman No. 3 filter paper (W. \& R. Balston Ltd., England) followed by a 47-mm glass fiber filter (Prefilter AP 25; Millipore Corporation, Bedford, MA). To avoid the time-consuming step of rotary evaporation, the culture filtrate was directly extracted four times with 1/10 volume of ethyl acetate in a 2-liter separating funnel. Pooled ethyl acetate extracts were subjected to rotary evaporation to give an oily residue. The oily residue was solubilized in $18 \mathrm{ml}$ of chloroform and left under a hood overnight to dry.

After drying, the crude toxin was dissolved in $5.4 \mathrm{ml}$ of ethanol. One-third of the sample $(1.8 \mathrm{ml})$ was diluted to $10 \mathrm{ml}$ with water and loaded onto a C18 reversed-phase Sep Pak cartridge (Millipore Corp.) that had been equilibrated in water. The cartridge was progressively eluted with $10 \mathrm{ml}$ each of $0,25,50,75$, and $100 \%$ acetonitrile in water ( $\mathrm{vol} / \mathrm{vol})$. This entire process was repeated two more times with the remainder of the ethanol-solubilized crude toxin, and all equivalent fractions were pooled. Each pooled fraction was subjected to rotary evaporation and the resulting oily residue was dissolved in $6 \mathrm{ml}$ of chloroform, transferred to a smaller vessel, dried under a hood overnight, and dissolved in $900 \mu \mathrm{l}$ of ethanol. Initial assays indicated that the majority of the toxic activity was contained in the $75 \%$ acetonitrile/water ( $\mathrm{vol} / \mathrm{vol}$ ) fraction. Consequently, only this fraction was used for the genotype evaluations.

Assay method. Seven-milliliter scintillation vials (Solvent Saver; Kimble, Vineland, NJ) were numbered and marked for each wheat genotype in three replications per run plus one control vial. Each of the three treatment vials received $840 \mu$ l of water and $60 \mu \mathrm{l}$ of ethanol-dissolved toxic fraction; control vials received $60 \mu \mathrm{l}$ of ethanol. Leaves were excised from 14-day-old plants with scissors and placed in the marked vials, one leaf per vial. To maintain leaf uniformity for all genotypes, only second leaves were chosen from robust plants in each pot, and leaves were cut to the same length. Vials containing the leaves were kept standing in a paperboard rack in a growth chamber at $21^{\circ} \mathrm{C}$ with a $16-\mathrm{h}$ photoperiod. After $24 \mathrm{~h}, 1 \mathrm{ml}$ of water was added to protect the leaves from desiccation. The experiment was repeated twice, with three replications per genotype for each of the three runs.

Leaves began showing wilting within $24 \mathrm{~h}$ of exposure to the toxic fraction, and sensitive genotypes were severely wilted within $72 \mathrm{~h}$ of exposure, when data were recorded. In contrast, control leaves did not change in appearance during this time. Wilting was evaluated on a continuous scale of 1 to 5 , which is proportional to the degree of wilting, accounting for both the proportion of leaf area wilted and the severity of wilting symptoms. On this scale, 1 indicates no change in leaf appearance and 5 indicates a fully wilted and dried or necrotic leaf (Fig. 1).

Statistical analyses. Because none of the control leaves showed visible symptoms, they were not included in the statistical analyses. Wilting data for the toxin-treated leaves from all three runs were subjected to analysis of variance (ANOVA) using the general linear models procedure (PROC GLM) of the Statistical Analysis System (SAS Institute Inc., Cary, NC). In the first analy-

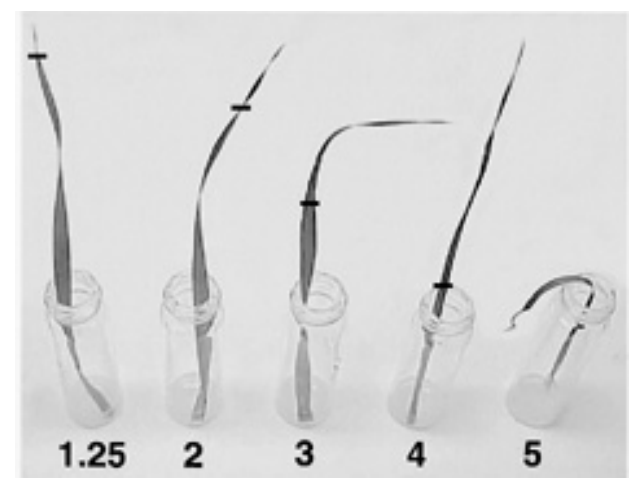

Fig. 1. Scale used to assess the degree of wilting of wheat leaves after $72 \mathrm{~h}$ of exposure to a toxic fraction produced by Cephalosporium gramineum. Wilting was evaluated on a continuous scale of 1 to 5 that is proportional to the degree of wilting, accounting for both the proportion of leaf area wilted and the severity of wilting symptoms. On this scale, 1 indicates no change in leaf appearance and 5 indicates a fully wilted and dried or necrotic leaf. Black bar on a leaf indicates the extent of wilting down the leaf. 
sis, we considered genotype, run, and genotype $\times$ run as the experimental factors. Because the genotype $\times$ run interaction was insignificant $(P=0.818)$, run and genotype $\times$ run were dropped and the data reanalyzed. Fisher's protected least significant difference (LSD) test $(P=0.05)$ was calculated to compare individual genotype means. Differences among the four taxonomic groups (common, club, durum, and synthetic) were evaluated by six preplanned linear contrasts.

Field experiments, locations and experimental design. Experiments were conducted in commercial fields near Dufur and Condon, OR. Both fields had a history of severe Cephalosporium stripe, and were planted in stubble mulch at mid-September planting dates to encourage disease severity. Elevation and mean annual precipitation were $900 \mathrm{~m}$ and $35.8 \mathrm{~cm}$ for the Condon site, and $600 \mathrm{~m}$ and $31.8 \mathrm{~cm}$ for the Dufur site.

The experiments were arranged in a randomized complete block design with three replications at Condon and four replications at Dufur. All genotypes evaluated in the laboratory/growth chamber experiment were included, except for spring genotypes Opata 85, Altar 84, and M6. Plots were either four or eight rows wide with

TABLE 1. Variance components for analysis of sensitivity of 112 recombinant inbred wheat lines to a toxic fraction produced by Cephalosporium gramineum

\begin{tabular}{lccc}
\hline Source of variation & $\mathrm{df}$ & Mean square & Variance expectation \\
\hline Genotype & $g-1$ & M3 & $\sigma_{g r}{ }^{2}+r \sigma_{g}{ }^{2}$ \\
Replications & $r-1$ & M2 & $\sigma_{g r}{ }^{2}+g \sigma^{2} r$ \\
Error & $(g-1)(r-1)$ & M1 & $\sigma_{g r}{ }^{2}=\sigma_{e}{ }^{2}$ \\
\hline
\end{tabular}

$35.6 \mathrm{~cm}$ between rows and either 7.5 or $30 \mathrm{~m}$ in length. Plot size variation was due to limitations in available area and seed stocks. Plots were planted 15 September 1999 at Condon and 16 September 1999 at Dufur with a plot drill at a rate of 200 seeds per square meter. Fertilization and other cultural practices were conducted by cooperating farmers and were standard for commercial production in the area.

Data collection and statistical analyses. Each plot was examined by two individuals at the late milk/early dough stage, to estimate the percentage of whiteheads (heads showing early maturity, which often have poor or no grain fill). Whitehead data for each location were subjected to ANOVA for a randomized complete block design using PROC GLM. To better satisfy the assumption of homogeneity of variance, data for Condon were first transformed to $\log _{10}(Y+0.5)$, and those of Dufur were transformed to $\log _{e}(Y+0.5)$. Fisher's protected LSD was calculated for comparison among individual genotypes. Pairwise differences between germ plasm groups (common, club, and durum) were evaluated by three preplanned linear contrasts. In addition, whitehead percentages in field plots and wilting ratings from the toxin assays for all 17 genotypes that were common to both the laboratory and field experiments were subjected to canonical correlation analysis using the Analyst application (SAS Institute).

Mapping population evaluation. The detached leaf assay was used to obtain toxin sensitivity data from individuals of the ITMI population. Because the toxin extracted from each batch of 9 liters of broth was standardized to evaluate 30 genotypes at a time, we evaluated the progeny in four different batches. Each time we included the insensitive parent (M6) and sensitive parent (Opata $85)$ as checks.

TABLE 2. Mean wilting reaction of 20 winter and spring wheat genotypes to a toxic fraction produced by Cephalosporium gramineum in the laboratory and percentage of whiteheads expressed by 17 winter wheat genotypes in naturally infested fields at two locations

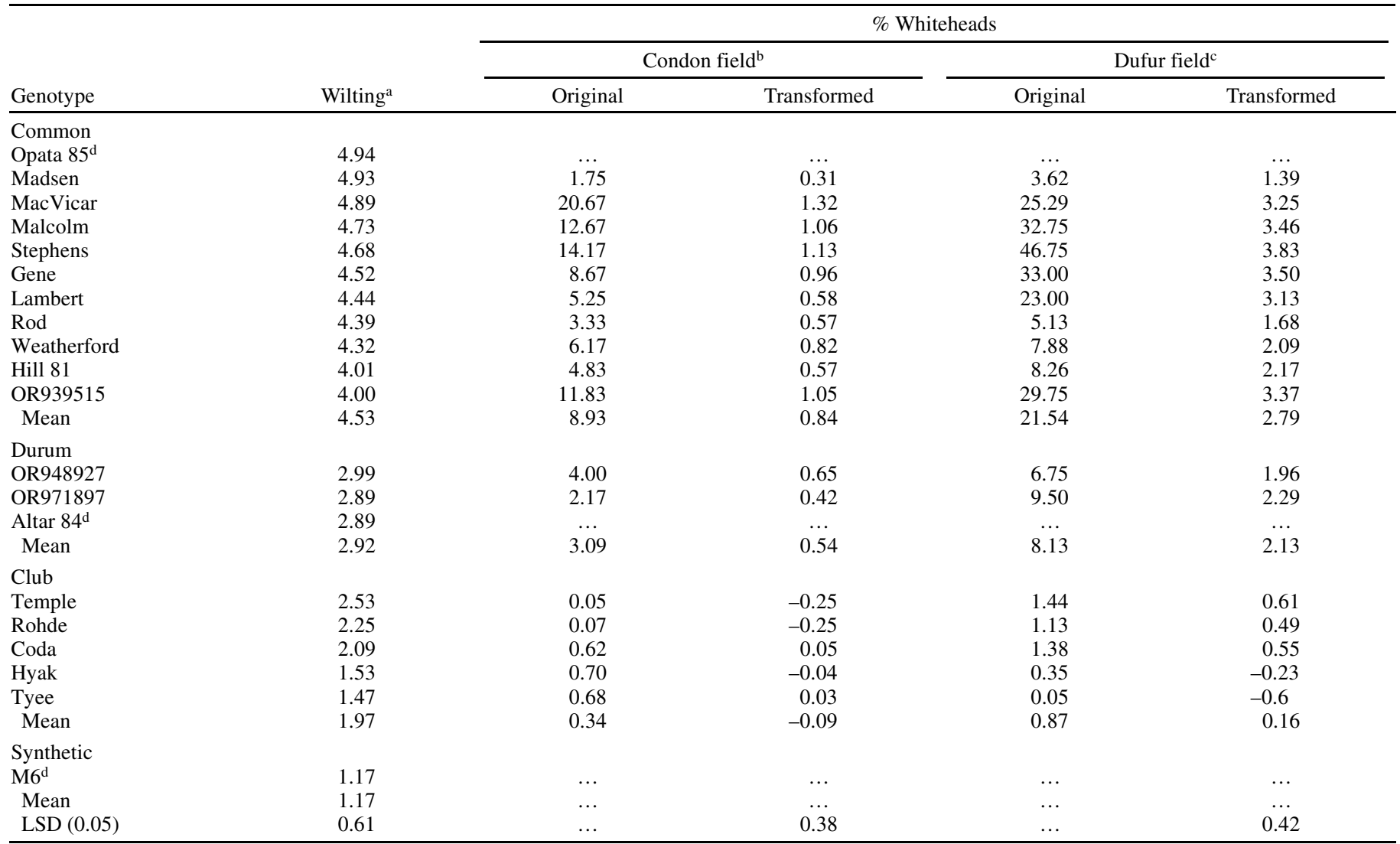

$\bar{a}$ Continuous scale with $1=$ no effect of toxic fraction on leaf appearance and $5=$ fully wilted and dried or necrotic leaf (Fig. 1). Data are means of three experiments, with three replicates per experiment.

${ }^{\mathrm{b}}$ Data are means of three replications, and the transformed scale was $\log _{10}(\%$ whiteheads +0.5$)$.

${ }^{c}$ Data are means of four replications, and the transformed scale was $\log _{e}(\%$ whiteheads +0.5$)$.

${ }^{\mathrm{d}}$ Genotype could not be included in the field experiments because it is a spring type. 
Heritability estimate. Considering the effects of the genotypes to be random, estimates of variance components were computed by equating mean squares to their expectations (Table 1). The genetic component of variance $\left(\sigma_{g}{ }^{2}\right)$ was estimated as $\sigma_{g}{ }^{2}=(\mathrm{M} 3-$ $\mathrm{M} 1) / r$. Heritability estimates were calculated on an entry basis as $h^{2}=\sigma_{g}{ }^{2} /\left(\sigma_{g}{ }^{2}+\sigma_{e}{ }^{2} / r\right)$, where $\sigma_{g}{ }^{2}$ and $\sigma_{e}{ }^{2}$ are the sample genotypic and error variances, respectively, and $r$ is the number of replications. The $90 \%$ confidence interval limits for estimates of heritability were calculated according to Knapp et al. (14).

\section{RESULTS}

Reaction of genotypes to the toxic fraction. The main effect of wheat genotype in the ANOVA was highly significant $(P \leq$ $0.0001)$. The common wheat genotypes were all highly sensitive to the toxic fraction (wilting rating of 4 or greater) (Table 2). Fisher's protected LSD indicates that there is significant variation among genotypes within the common and club groups, but no overlap between these two groups. The three durum wheats showed highly similar reactions, and were intermediate between that of the common and the club groups. The synthetic wheat M6, which is a parent of the ITMI population, showed the highest level of insensitivity. Fortuitously, the other parent of the ITMI population (Opata 85) was the most sensitive genotype evaluated, thus providing an opportunity for studying inheritance of sensitivity to the toxic fraction among progeny of this cross. Linear contrasts were highly significant $(P \leq 0.001)$ for the six pairwise combinations among the four germ plasm groups (Table 3).

Field reactions. Disease levels were lower (Table 2) and variation among plots was greater (data not shown) at the Condon site than at the Dufur site. Nonetheless, rankings among genotypes were similar between sites (Table 1), with a correlation coefficient of $0.90(P \leq 0.0001)$, and the main effect of wheat genotype was highly significant in the ANOVA for each site $(P \leq 0.0001)$. On average, the two durum wheats were less susceptible than the common wheats (Table 2), although there was some overlap with the more resistant common wheat genotypes (Table 2). The club wheats were consistently more resistant than either common or durum wheats (Tables 2 and 3 ).

TABLE 3. Linear contrasts between wheat germ plasm groups for wilting in reaction to a toxic fraction produced by Cephalosporium gramineum in the laboratory and percentage of whiteheads when grown in a naturally infested field at each of two sites (Condon and Dufur)

\begin{tabular}{lll}
\hline Contrast & Group means & 95\% Confidence interval \\
\hline Laboratory & & \\
$\quad$ Common vs. club & 4.53 vs. 1.97 & 1.46 to 2.03 \\
Common vs. durum & 4.53 vs. 2.92 & 2.28 to 2.76 \\
Common vs. synthetic & 4.53 vs. 1.17 & 2.90 to 3.82 \\
Club vs. durum & 1.97 vs. 2.92 & 0.45 to 1.09 \\
Club vs. synthetic & 1.97 vs. 1.17 & 1.11 to 2.11 \\
$\quad$ Durum vs. synthetic & 2.92 vs. 1.17 & 0.36 to 1.32 \\
$\quad$ Condon field & & \\
$\quad$ Common vs. club & 0.84 vs. 0.08 & 0.15 to 0.45 \\
Common vs. durum & 0.84 vs. 0.54 & 0.71 to 1.13 \\
$\quad$ Club vs. durum & 0.08 vs. 0.54 & 0.39 to 0.85 \\
$\quad$ & \\
Dufur field & & \\
Common vs. club & 2.79 vs. 0.16 & 0.53 to 0.85 \\
Common vs. durum & 2.79 vs. 2.10 & 2.39 to 2.87 \\
Club vs. durum & 0.16 vs. 2.10 & 1.68 to 2.20 \\
\hline
\end{tabular}

a All differences between group means were significant at $P \leq 0.001$, based on linear contrasts.

${ }^{\mathrm{b}}$ Data on wilting were taken on a continuous scale of 1 to 5 ( $1=$ no wilting and $5=$ maximum wilting) after $72 \mathrm{~h}$ of exposure to the toxic fraction. Data are means of three experiments, with three replications per experiment.

${ }^{\mathrm{c}}$ Percentage of whitehead data on three replications transformed to $\log _{10}(Y+0.5)$

d Percentage of whitehead data on four replications transformed to $\log _{e}(Y+0.5)$.
Comparison of laboratory assay to field data. There was more variation among genotypes within germ plasm groups for the field data than for the detached leaf assay (Table 2). Nonetheless, rankings of mean disease levels for the three germ plasm groups tested in the field were the same as for the toxin assay, with the common wheats most susceptible, the club wheats most resistant, and the durum wheats intermediate. Wilting symptoms measured in growth chambers were significantly $(P=0.0001)$ correlated with percentage of whiteheads estimated at each site (Figs. 2 and 3).

Mapping population evaluation. Frequency distribution of the wilting data (Fig. 4) suggests a continuous distribution skewed toward insensitivity. Seventeen of the progeny were numerically less sensitive than M6, and three were more sensitive than Opata 85 , although none of these differences were significant at $P=$ 0.05, based on either Duncan's multiple range or Fisher's LSD

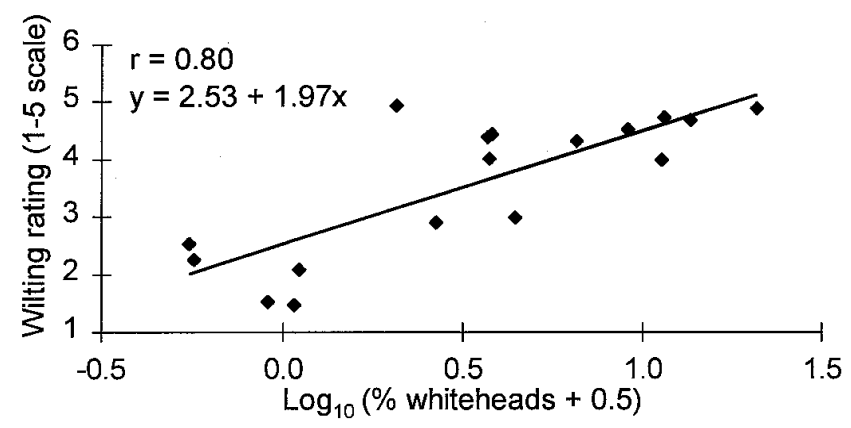

Fig. 2. Correlation of leaf wilting in the laboratory in response to a toxic fraction produced by Cephalosporium gramineum with percent whiteheads produced by 17 wheat genotypes in a naturally infested field in Condon, OR.

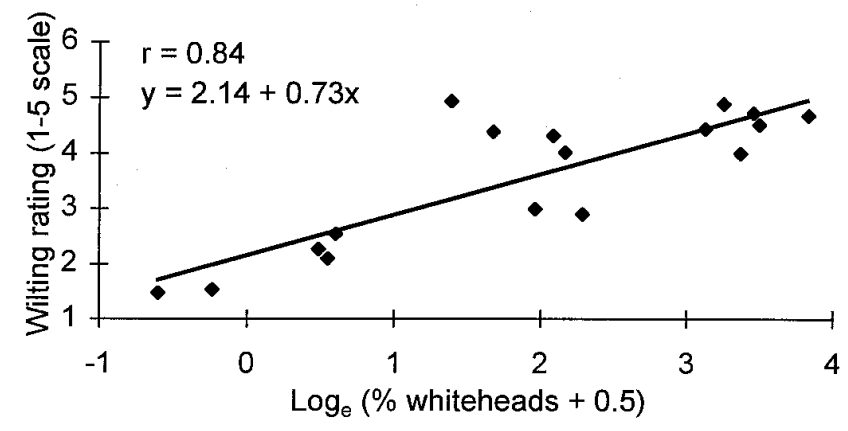

Fig. 3. Correlation of leaf wilting in the laboratory in response to a toxic fraction produced by Cephalosporium gramineum with percent whiteheads produced by 17 wheat genotypes in a naturally infested field in Dufur, OR.

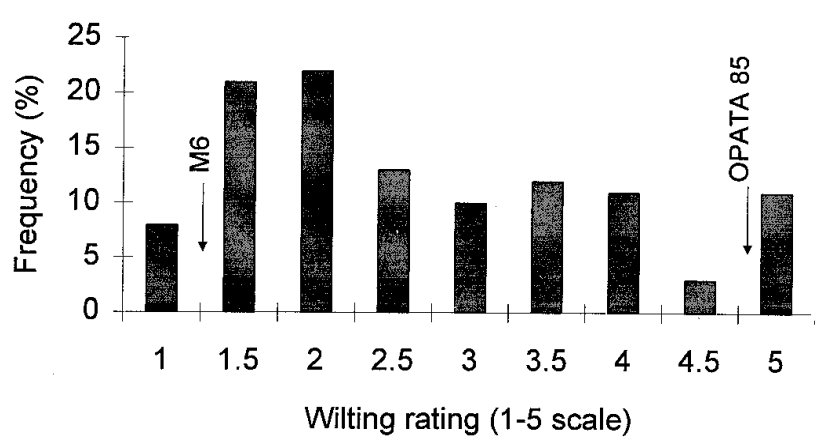

Fig. 4. Frequency distribution of wilting for 112 recombinant inbred line progeny resulting from a cross between toxin-sensitive parent Opata 85 and toxin-insensitive parent M6 after exposure to a toxic fraction produced by Cephalosporium gramineum. 
test. ANOVA (Table 4) indicated that differences among the progeny were highly significant $(P \leq 0.0001)$ with respect to toxin sensitivity. Based on variance components analysis, the genetic component of variance was very large, with heritability on a genotype mean basis at 0.88 . The $90 \%$ confidence interval for the estimate of heritability was $0.85-0.91$.

\section{DISCUSSION}

Our results are consistent with the hypothesis that toxin insensitivity is an important mechanism of resistance to Cephalosporium stripe. Sensitivity to the toxic fraction was significantly correlated with percentage of whiteheads in two field trials. Further, the common, durum, and club germ plasm groups ranked the same for both toxin sensitivity and disease reaction in the field. M6, Altar 84 , and Opata 85 could not be tested in the field because they are spring types, whereas Cephalosporium stripe is mainly a disease of fall-sown wheat $(1,5)$. However, preliminary studies with exposure of these genotypes to the pathogen in a liquid culture system in the greenhouse showed M6, Altar 84, and Opata 85 to be resistant, intermediate, and susceptible to Cephalosporium stripe, respectively (O. Riera-Lizarazu, unpublished data), which is consistent with their reaction to the toxic fraction. The common wheat genotypes were all sensitive to the toxic fraction but showed a substantial range of reactions in the field. It is important to note, however, that we found no case of an insensitive genotype being susceptible in the field. These results suggest that toxin insensitivity may be an important mechanism of resistance to Cephalosporium stripe, but that other mechanisms are operative as well; similar results have been obtained for Fusarium head blight of wheat and toxin (19).

Differences in sensitivity to the toxic fraction were most notable among the four germ plasm groups. Both common and club wheats are hexaploids that carry the A, B, and D genomes, but the club wheats originated from a different and substantially smaller gene pool than the common wheats. Durum wheat (T. turgidum) is a tetraploid that contains only the A and B genomes. The hexaploid synthetic wheat that we studied derived its D genome from A. tauschii, which is a well-known source of resistance to many wheat diseases $(10,20,33,37)$. This association of germ plasm groups with toxin insensitivity should be interpreted with caution, however, because only three durums and one synthetic wheat were evaluated in this study.

Symptomology depended on the concentration of the toxic fraction. We observed chlorosis of wheat leaves at low concentration $(20 \mu \mathrm{l} / \mathrm{ml})$, but this chlorosis did not reliably distinguish among wheat genotypes. At higher concentration $(60 \mu \mathrm{l} / \mathrm{ml})$, we obtained distinct wilting symptoms that consistently distinguished wheat genotypes. Similarly, Kobayashi and Ui (16) observed chlorosis after 3 days of exposure of leaves to toxin and wilting in 5 days with a concentration of $25 \mu \mathrm{g} / \mathrm{ml}$ of Graminin A. Unfortunately, we have no way of knowing what proportion of total solute contributed activity in our assays. In the field, C. gramineum produces a wide array of symptoms depending on favorableness of conditions for disease. We have found the percentage of whiteheads, a severe symptom, to be a much more consistent and reproducible indication of resistance in the field than less severe symptoms such as leaf striping (C. C. Mundt, unpublished data).

TABLE 4. Analysis of variance for wilting reaction of the International Triticeae Mapping Initiative population after exposure to a toxic fraction produced by Cephalosporium gramineum

\begin{tabular}{lrrccc}
\hline $\begin{array}{l}\text { Source of } \\
\text { variation }\end{array}$ & df & $\begin{array}{c}\text { Sums of } \\
\text { squares }\end{array}$ & $\begin{array}{c}\text { Mean } \\
\text { squares }\end{array}$ & $F$ & $\operatorname{Pr}>F$ \\
\hline Genotype & 111 & 472.01 & 4.2523 & 8.94 & 0.0001 \\
Replications & 2 & 2.00 & 1.0010 & 2.10 & 0.1243 \\
Error & 222 & 105.57 & 0.4756 & $\ldots$ & $\ldots$ \\
\hline
\end{tabular}

We used the $75 \%$ acetonitrile reversed-phase fraction of the crude extract for our study. Although we detected evidence for the existence of Graminin A in the crude toxin preparation by thin layer chromatography, we did not further analyze this specific fraction for the presence of Graminin A or other compounds. Thus, Graminin A alone, or with other pathogen-produced compounds, could have contributed to the toxic effect measured in this study. Further characterization of the toxic fraction may provide additional information regarding the role of toxins in the pathogenesis of $C$. gramineum.

Many studies of plant pathogen toxins have involved highly host-selective interactions and qualitative inheritance of both susceptibility and virulence $(3,27)$, although there are exceptions (19). Studies of resistance to Cephalosporium stripe by other workers $(21,25)$ are suggestive of incomplete expression of resistance and quantitative inheritance of disease reaction for Cephalosporium stripe. These observations prompted us to study toxin sensitivity in a mapping population of 112 progeny, derived from crossing the highly toxin-sensitive parent Opata 85 and the insensitive synthetic parent M6. The resulting frequency distribution suggests quantitative inheritance but with a very high heritability (0.88) that would allow for rapid response to selection. However, these results should be viewed with some caution, because we do not know if the ITMI population is representative of wheat in general. Evaluation of the ITMI progenies for disease reaction would be useful in further elucidating the association between toxin insensitivity and disease resistance. This remains problematic, however, because the mapping population is in a spring wheat background. Efforts are underway to use the ITMI population to identify quantitative trait loci for toxin insensitivity and Cephalosporium stripe resistance.

Variability and environmental sensitivity in expression of Cephalosporium stripe make field screening difficult, especially in early generations of breeding material, when limited seed stocks are available (6). Our study may thus provide options for more efficient screening of breeding material through direct assay with the toxic fraction in a controlled environment. Eliminating the most sensitive genotypes with a laboratory-based method could greatly reduce the number of genotypes to be tested in the field, thus reducing costs and allowing for more complete evaluation of the retained genotypes. Subsequent selection of the more resistant types after exposure to the pathogen in the field would increase the probability that mechanisms, in addition to toxin insensitivity, were being selected.

\section{LITERATURE CITED}

1. Bailey, J. E., Lockwood, J. L., and Wiese, M. V. 1982. Infection of wheat by Cephalosporium gramineum as influenced by freezing of roots. Phytopathology 72:1324-1328.

2. Bockus, W. W., O'Connor, J. P., and Raymond, P. J. 1983. Effect of residue management method on incidence of Cephalosporium stripe under continuous winter wheat production. Plant Dis. 67:1323-1324.

3. Brown, C. A., and Hunger, R. M. 1993. Production of a chlorosis inducing, host-specific, low molecular weight toxin by isolates of $P y$ renophora tritici-repentis, cause of tan spot of wheat. J. Phytopathol. 137:221-232.

4. Bruehl, G. W. 1957. Cephalosporium stripe disease of wheat. Phytopathology 47:641-649.

5. Bruehl, G. W. 1968. Ecology of Cephalosporium stripe disease of winter wheat in Washington. Plant Dis. Rep. 52:590-594.

6. Bruehl, G. W., Lai, P., and Huisman, O. 1964. Isolation of Cephalosporium gramineum from buried, naturally infested host debris. Phytopathology 54:1035-1036.

7. Bruehl, G. W., Murray, T. D., and Allan, R. E. 1986. Resistance of winter wheats to Cephalosporium stripe in the field. Plant Dis. 70:314-316.

8. Commonwealth Mycological Institute. 1976. CMI Description of Pathogenic Fungi and Bacteria No. 501. Kew, Surrey, England.

9. Cowger, C., and Mundt, C. C. 1998. A hydroponic seedling assay for resistance to Cephalosporium stripe of wheat. Plant Dis. 82:1126-1131.

10. Cox, T. S., Raupp, W. J., Wilson, D. L., Gill, B. S., Leath, S., Bockus, W. W., and Browder, L. E. 1992. Resistance to foliar disease in a collection 
of Triticum tauschii germ plasm. Plant Dis. 76:1061-1064.

11. Creatura, P. J., Safir, G. R., Scheffer, R. P., and Sharkey, T. D. 1981. Effects of Cephalosporium gramineum and a toxic metabolite on stomatal conductance of wheat. Physiol. Plant Pathol. 19:313-323.

12. Grey, E. G., and Noble, M. 1960. Cephalosporium stripe in Scotland. FAO Plant Prot. Bull. 8:46.

13. Johnston, R. H., and Mathre, D. E. 1972. Effect of infection by Cephalosporium gramineum on winter wheat. Crop Sci. 12:817-819.

14. Knapp, S. J., Stroup, W. W., and Ross, W. M. 1985. Exact confidence intervals for heritability on a progeny mean basis. Crop Sci. 25:192-194.

15. Kobayashi, K., and Ui, T. 1977. Graminin A, a new toxic metabolite from Cephalosporium gramineum Nisikado \& Ikata. J. Chem. Soc. Chem. Commun. 21:774.

16. Kobayashi, K., and Ui, T. 1979. Phytotoxicity and antimicrobial activity of Graminin A, produced by Cephalosporium gramineum, the causal agent of Cephalosporium stripe disease of wheat. Physiol. Plant Pathol. 14:129-133.

17. Lai, P., and Bruehl, G. W. 1966. Survival of Cephalosporium gramineum in naturally infested wheat straws in soil in the field and in the laboratory. Phytopathology 56:213-218.

18. Latin, R. X., Harder, R. W., and Weise, M. V. 1982. Incidence of Cephalosporium stripe as influenced by winter wheat management practices. Plant Dis. 66:229-230.

19. Lemmens, M., Resinger, A., Burstmayr, H., and Ruckenbauer, P. 1994. Breeding for head blight (Fusarium spp.) resistance in wheat: Development of a mycotoxin-based selection method of seedlings. Acta Hortic. 355:223-232.

20. Lutz, J. 1992. Powdery mildew resistance in Aegilops tauschii coss., in synthetic hexaploid wheats. Genet. Resour. Crop Evol. 41:151-158.

21. Martin, J. M., Mathre, D. E., and Johnston, R. H. 1983. Genetic variation for reaction to Cephalosporium gramineum in four crosses of winter wheat. Can. J. Plant Sci. 63:623-630.

22. Martin, J. M., Mathre, D. E., and Johnston, R. H. 1986. Winter wheat genotype responses to Cephalosporium gramineum inoculum levels. Plant Dis. 70:421-423.

23. Mathre, D. E., and Johnston, R. H. 1975. Cephalosporium stripe of winter wheat: Infection process and host response. Phytopathology 65:1244-1249.

24. Mathre, J. M., and Johnston, R. H. 1983. Cephalosporium stripe of winter wheat, procedures for determining host response. Crop Sci. 15:
591-594.

25. Morton, J. B., and Mathre, D. E. 1980. Identification of resistance to Cephalosporium stripe in winter wheat. Phytopathology 70:812-817.

26. Nisikado, Y., Matsumoto, H., and Yamauti, K., 1934. Studies on a new Cephalosporium which causes the stripe disease of wheat. Rev. Appl. Mycol. 13:623-624.

27. Payne, G., Kono, Y., and Daly, J. M. 1980. A comparison of purified host specific toxin from Helminthosporium maydis, race $\mathrm{T}$, and its acetate derivative on oxidation by mitochondria from susceptible and resistant plants. Plant Physiol. 65:785-791.

28. Pool, R. A. F., and Sharp, E. L. 1969. Possible association of polysaccharide and an antibiotic with the disease cycle of Cephalosporium stripe. Phytopathology 59:1763-1764.

29. Raymond, P. J., and Bockus, W. W. 1984. Effect of seeding date of winter wheat on incidence, severity, and yield loss caused by Cephalosporium stripe in Kansas. Plant Dis. 68:665-667.

30. Shefelbine, P. A., and Bockus, W. W. 1989. Decline of Cephalosporium stripe by monoculture of moderately resistant winter wheat cultivars. Phytopathology 79:1127-1131.

31. Slope, D. B. 1962. Cephalosporium stripe disease of wheat. Plant Pathol. $11: 160$.

32. Spalding, D. H., Bruehl, G. W., and Foster, R. J. 1961. Possible role of pectinolytic enzymes and polysaccharide in pathogenesis by Cephalosporium gramineum in wheat. Phytopathology 51:227-235.

33. Thompson, J. P., and Haak, M. I. 1997. Resistance to root lesion nematode (Pratylenchus thornei) in Aegilops tauschii coss., the D genome donor to wheat. Aust. J. Agric. Res. 48:553-559.

34. Van Deynze, A. E., Dubcovsky, J., Grill, K. S., Nelson, J. C., Sorrells, M. E., Dvorak, J., Gill, B. S., Lagudah, E. S., McCouch, S. R., and Apple, R. 1995. Molecular - genetic map for group 1 chromosomes of Triticea species: Their relation to chromosomes in rice and oat. Genome 38:45-59.

35. Van Wert, S. L., Ravenscroft, A. V., and Fulbright, D. W. 1984. Screening wheat lines as seedlings for resistance to Cephalosporium gramineum. Plant Dis. 68:1036-1038.

36. Wiese, M. V. 1972. Colonization of wheat seedlings by Cephalosporium gramineum in relation to symptom development. Phytopathology 62: 1013-1018.

37. Yildirim, A., Jones, S. S., Murray, T. D., Cox, T. S., and Line, R. F. 1995. Resistance to stripe rust and eyespot diseases of wheat in Triticum tauschii. Plant Dis. 79:1230-1236. 